OPEN ACCESS

Edited by:

Yann Joly,

McGill University, Canada

Reviewed by:

Nicole Palmour,

McGill University, Canada

Charles J. Vukotich Jr,

University of Pittsburgh, United States

${ }^{*}$ Correspondence:

Bewunetu Zewude

bewunetuzewude@gmail.com

Specialty section:

This article was submitted to Infectious Diseases - Surveillance,

Prevention and Treatment,

a section of the journal

Frontiers in Public Health

Received: 29 May 2021

Accepted: 07 July 2021

Published: 06 August 2021

Citation:

Zewude B, Melese B, Habtegiorgis T,

Tadele M and Solomon W (2021)

Compliance With Protective

Behavioral Recommendations in the

Outbreak of COVID-19 Among People Working in the Urban-Based Informal

Economy in Southern Ethiopia.

Front. Public Health 9:716814.

doi: 10.3389/fpubh.2021.716814

\section{Compliance With Protective Behavioral Recommendations in the Outbreak of COVID-19 Among People Working in the Urban-Based Informal Economy in Southern Ethiopia}

\author{
Bewunetu Zewude ${ }^{1 *}$, Belayneh Melese ${ }^{2}$, Tewodros Habtegiorgis ${ }^{1}$, Mihret Tadele ${ }^{1}$ and \\ Weynishet Solomon ${ }^{1}$
}

${ }^{1}$ Department of Sociology, Wolaita Sodo University, Sodo, Ethiopia, ${ }^{2}$ Department of Civics and Ethical Studies, Wolaita Sodo University, Sodo, Ethiopia

Regardless of the advocacies made by the media and numerous organizations about the need for preventing the spread of COVID-19, there still exists a gap as far as compliance to regular implementation of the preventive mechanisms within communities is concerned. The purpose of the present study was, therefore, to examine compliance to personal protective behavioral recommendations to contain the spread of COVID-19 among urban residents engaged in the informal economic activities in Wolaita Sodo town, Southern Ethiopia. A cross-sectional study design was used where quantitative data were collected through the survey research method. Three hundred and eighty-four participants of the urban-based informal economy were randomly selected and contacted in their own natural settings with an interviewer-administered questionnaire. Data were inserted into SPSS software for analysis that involved both descriptive and inferential statistics, including frequency and percentage distributions, binomial and multinomial logistic regressions. The results of the research indicated that only $35.4 \%$ of the respondents regularly wore a mask. In addition, $54.9 \%$ of the survey participants disclosed that they do not clean their hands with disinfectants after touching objects under circumstances where they cannot get access to water and soap. Moreover, the most commonly reported reason of respondents for non-compliance to regular wearing of a mask has been its inconvenience or discomfort (62.8\%), followed by the need to appear indifferent because most people around them do not wear a mask (25.2\%). Furthermore, experiences of the respondents of regularly wearing a mask are significantly associated with regular attendance of the media regarding the preventive mechanisms of COVID-19 (OR = 0.224; $P<0.001$; 95\%C.I: 0.109-0.460), knowledge of someone ever infected by COVID-19 (OR $=0.402 ; P<0.05 ; 95 \%$ C.I: $0.190-0.851)$, the belief that COVID-19 causes a severe illness (OR $=0.444 ; P<0.05$; 95\%C.I: 0.201-0.980), and perception of the likelihood of dying as a result of infection by COVID-19 (OR $=0.374$; $P<0.01 ; 95 \%$ C.I: 0.197-0.711). The authors have found a low level of compliance to the 
recommended safety measures, especially wearing of masks. It is, therefore, important that continued efforts of raising awareness should be done by all the concerned bodies. Above all, urban safety net programs that aim at keeping such social groups at home, at least during the critical wave of the pandemic, should also be strengthened.

Keywords: compliance, COVID-19, informal economy, washing hands, wearing mask

\section{INTRODUCTION}

It is widely reported that the COVID-19 pandemic has entered a new stage with rapid spread in almost all the countries of the world claiming the lives of more than 3 million people (1). It is expected, and of course, practically observed in some parts of the world that the healthcare systems face shortages of personnel and medical equipment supplies to treat the critically ill during the pandemic (2). Therefore, countries worldwide are encouraged to assess the existing community engagement structures and to use community engagement approaches to support contextually specific, acceptable, and appropriate COVID-19 prevention and control measures $(3,4)$. In addition, all members of the society must understand and practice measures for self-protection and for the prevention of transmission of infection to others $(5,6)$.

In developing countries such as Ethiopia where access to COVID-19 vaccine to every citizen is difficult to achieve, the most important way to control the disease among the populations is regular hand washing, regular wearing of face masks, the use of disinfectants, and the prevention of contact with the face and mouth after interacting with the infected environment (7). In response to the outbreak and spread of COVID-19, many countries have been using a combination of containment and mitigation activities with the intention of delaying major flow of patients and decreasing the demand for hospital beds, including different levels of contact tracing and isolation; avoiding touching of eyes, nose, and mouth; routine cleaning and disinfection of the environment; wearing face mask; social distancing; preparation of health systems for an outpour of severely ill patients who require isolation, oxygen, and mechanical ventilation; strengthening health facility infection prevention and control, with special attention to nursing home facilities; and postponement or cancelation of large-scale public gatherings $(5,6)$.

Nevertheless, regardless of the advocacies made by the media and numerous organizations about the need for preventing the spread of the pandemic, including the various ways of transmission, there still exists a gap as far as compliance to regular implementation of the preventive mechanisms within communities is concerned (8). Although many countries have been taking different preventive measures, some of these interventions became ineffective in stopping or at least reducing the fast spread of the pandemic which continued claiming

Abbreviations: SPSS, Statistical Package for Social Sciences; BA, Bachelor of Arts; BSc, Bachelor of Science; CSA, Central Statistical Agency; C.I, Confidence Interval; ERC, European Research Council; ILO, International Labor Organization; OR, Odds Ratio. millions of lives (9). According to Reference (6), the indications for personal protective equipment should be based on many circumstances, including the setting, target audience, risk of exposure, and the transmission dynamics of the pathogen. In addition, the overuse or misuse of personal protective equipment will have a further impact not only on its effectiveness of preventing the pandemic, but also in inducing shortages on the supply, and hence on its accessibility to the rest of the population.

Findings of previous researches (10-13) undertaken in Ethiopia reveal a mix of both high and low knowledge of people toward COVID-19. A study by (8) found that more than half (54.11\%) of the research participants have inadequate knowledge about the prevention of COVID-19 in which sex, age, residence, educational status, experiences of seeking information from healthcare workers, social media, and mass media are the factors affecting such knowledge among the study population. On the other hand, another study undertaken in Addis Ababa, Ethiopia, by Desalegn et al. (14) found a positive attitude held among most $(60.7 \%)$ of the respondents.

The presence of a strong relationship between the perceived credibility of information sources about COVID-19 and the engagement of people in self-protective behaviors has been found by Lep et al. (15). According to the study, research participants tend to exhibit relatively lower trust on the information from mass media, social media, politicians, and political institutions whereas they tend to trust information from medical professionals and scientists. It was suggested that information about COVID-19 from credible sources would lead to better protective behaviors among the public, which will help to contain the spread of the pandemic. Tomczyk et al. (16) found high compliance (25\%) with all recommendations; public compliance $(51 \%)$, with high compliance regarding public but not personal behaviors; and low compliance (24\%) with most behavioral recommendations that help to contain the infection of COVID-19 where low compliance is associated with male sex, younger age, and lower public stigma.

In addition to its impact on the health of workers and their families, COVID-19 adversely affects specific societal groups who are more vulnerable to labor market conditions, especially unprotected workers, including the self-employed, casual, and gig workers, who are likely to be disproportionately hit by the virus as they do not have access to paid or sick leave mechanisms, and are less protected by conventional social protection mechanisms and other forms of income smoothing (17). According to Reference (18), the populations most at risk are those that depend heavily on the informal economy, occupy areas prone to shocks, have inadequate access to social services or political influence, have limited capacities and opportunities to cope and adapt, and 
people who have no or limited access to technologies. In this regard, self-employed people working in areas having no regular income in Ethiopia, including youth and women involved in the informal economic activities, motorbike or taxi service providers, shoe-cleaners, lottery ticket sellers, and people engaged in all forms of daily labor can be considered as social groups most affected by the pandemic. Members of such social groups are double burdened not only because of their susceptibility to the disease but also that their livelihood is more likely to be severely affected by the pandemic during periods of economic and social lockdowns. The objective of the present research was, therefore, to explore the patterns of compliance to the use of protective devices (non-pharmaceutical interventions) to contain the spread of COVID-19 among the urbanites working in the informal economies in Southern Ethiopia.

\section{METHODS AND MATERIALS}

\section{Research Design}

A cross-sectional study was carried using quantitative research approach. Through the survey method, quantitative data were collected from a sample of people working in the urban-based informal economy.

\section{Selection of Research Participants}

The target group of the present research is the "urban poor" who are not able to earn a regular income as a result of working in the informal urban economy. Members of such social groups must always go to work to secure their daily bread. In doing so, these individuals should either stand amid or frequently move around relatively large gatherings of people, which puts them at a higher risk of infection by COVID-19. Moreover, living in the highly unpredictable tomorrow due to the irregular income does not allow members of this group to stay at home to protect themselves even during the critical periods of the pandemic. Therefore, it is important that they adhere to at least some of the personal protective behavioral recommendations such as wearing a mask and cleaning hands. Consequently, we have considered the inclusion of people commonly known to work in the urban informal economies including motorbike or taxi service providers, shoe-shine boys and girls, daily laborers, street vendors, lottery ticket sellers, and women working in the daily small markets (locally known as gullit). In order to determine the sample size, the researchers applied Cochran's (1977) formula for calculating the sample size of an unknown population as:

$$
n=\frac{z^{2} \times p(1-p)}{e^{2}}=1.96^{2} \times 0.5(1-0.5) / 0.05^{2}=384
$$

where $n$ is the sample size, $z$ is the selected critical value of desired confidence level, $p$ is the estimated proportion of an attribute that is present in the population. Then, the final sample units were chosen on the basis of probability proportionate to the size sampling technique. The major inclusion criteria for sample selection were as follows: being the permanent resident of Wolaita Sodo town (having an urban residential background), employment or self-employment in the informal urban economy as a source of livelihood, and willingness to participate in the survey. From the 384 questionnaires used to collect data, 379 items were found to be correctly completed, making the response rate $98.7 \%$.

\section{Research Method and Source of Data}

Primary data were gathered mainly through the use of the survey research method. A self-administered questionnaire was prepared in English and then translated in to the local (Amharic) language. Then, data collectors, all of whom were instructors of sociology and civics and ethical education departments, were trained about the items in the questionnaire and all the things to be done in the process of data collection. Following this, a permission letter was secured from the concerned body of Wolaita Sodo University. Next, a pilot test was undertaken to prove the compatibility of the questionnaire on $5 \%$ of respondents having similar characteristics with the actual survey population. On the basis of feedback and comments obtained from the pilot survey, slight improvements were made to the instrument of data collection. The same questionnaire, having similar items, was duplicated according to the already determined sample size. Finally, the actual data collection activity was held in April and May 2021 under the supervision of the principal investigator. Respondents were told to freely raise any question that is unclear to them. The reliability of the instrument was checked through internal consistency of the response items using Cronbach's $\alpha$, whereas both content and face validity measures were used to maintain their validity.

\section{Instrument Design}

The questionnaire that served as an instrument of data collection in our research was partly taken from the studies of Lep et al. (15), Tomczyk et al. (16), and Zewude and Habtegiorgis (19) and adapted to the purpose at hand, whereas most other questions were developed by the researchers. The questionnaire mainly consists of two sections, namely, questions seeking the socio-demographic background of respondents and questions aimed at assessing the attitude of the research participants and experiences of implementing the personal protective behavioral recommendations. The first (background) section of the tool comprises variables such as sex, age, education, marital status, and the presence of children. In addition, this part also includes questions that aim at measuring perceptions of the respondent of COVID-19 and their previous contact or experience with the disease. For instance, respondents were asked if they believe that COVID-19 really exists in Ethiopia in general and the study area in particular, if they knew someone ever infected by or died of COVID-19, whether they believe that they can be infected by COVID-19, and their belief about whether they are likely to die from COVID-19, all with response categories of (1) Yes and (2) No.

The second section of the questionnaire aimed at measuring the experiences of the respondents in practicing the common personal protective behavioral recommendations. It involves questions such as "Do you regularly wear a mask?" "Do you frequently wash your hands after touching objects?", and "Where you cannot get access to water and soap, do you 
TABLE 1 | Socio-demographic background of respondents.

\begin{tabular}{|c|c|c|}
\hline Variables & Categories & Frequency (\%) \\
\hline \multirow[t]{2}{*}{ Sex } & Male & 218 (57.5\%) \\
\hline & Female & $161(42.5 \%)$ \\
\hline \multirow[t]{5}{*}{ Educational status } & Never attended school & 49 (12.9\%) \\
\hline & Primary (1-8) level & $96(25.3 \%)$ \\
\hline & Secondary (9-12) level & $112(29.6 \%)$ \\
\hline & College diploma & 58 (15.3\%) \\
\hline & BA/BSc degree & 64 (16.9\%) \\
\hline \multirow[t]{4}{*}{ Marital status } & Never married & $224(59.1 \%)$ \\
\hline & Married & 136 (35.9\%) \\
\hline & Divorced & $12(3.2 \%)$ \\
\hline & Widowed & $7(1.8 \%)$ \\
\hline \multirow[t]{2}{*}{ Do you have children? } & Yes & 127 (33.5\%) \\
\hline & No & $252(66.5 \%)$ \\
\hline \multirow[t]{2}{*}{ Do you regularly attend media regarding the preventive mechanisms of COVID-19? } & Yes & 258 (68.1\%) \\
\hline & No & $121(31.9 \%)$ \\
\hline \multirow[t]{2}{*}{ Do you believe that COVID-19 really exists in Ethiopia? } & Yes & $274(72.3 \%)$ \\
\hline & No & $105(27.7 \%)$ \\
\hline \multirow[t]{2}{*}{ Do you believe that COVID-19 really exists in Wolaita Sodo town (study area)? } & Yes & $214(56.5 \%)$ \\
\hline & No & $165(43.5 \%)$ \\
\hline \multirow[t]{2}{*}{ Do you know someone ever infected by COVID-19? } & Yes & $76(20.1 \%)$ \\
\hline & No & $303(79.9 \%)$ \\
\hline \multirow[t]{2}{*}{ Do you know someone died of COVID-19? } & Yes & $60(15.8 \%)$ \\
\hline & No & $319(84.2 \%)$ \\
\hline \multirow[t]{2}{*}{ Do you think that you can be infected by COVID-19? } & Yes & $169(44.6 \%)$ \\
\hline & No & $210(55.4 \%)$ \\
\hline \multirow[t]{2}{*}{ Do you think that COVID-19 causes severe illness? } & Yes & $262(69.1 \%)$ \\
\hline & No & $117(30.9 \%)$ \\
\hline \multirow[t]{3}{*}{ Do you think that you are likely to die if infected by COVID-19? } & Yes & 165 (43.5\%) \\
\hline & No & 214 (56.5\%) \\
\hline & Total & 379 (100\%) \\
\hline
\end{tabular}

clean your hands with disinfectants after touching objects?" all with response categories of "yes" and "no". Moreover, the section also includes questions that intend to assess the extent to which respondents believe in the effectiveness of the protective behavioral recommendations. For instance, we have asked respondents "Do you believe that a mask can prevent the transmission of COVID-19?" and "Do you believe that cleaning hands immediately after touching any object can prevent COVID-19?" with response categories of "yes" and "no". Furthermore, with the expectation of non-compliance to the behavioral recommendations, potential reasons for such noncompliance were also included in the section.

\section{Method of Data Analysis}

The questionnaires returned from the field were first checked against completeness. The correctly completed ones were then inserted into a statistical package for social sciences software. Data generated from the software were presented using both descriptive and inferential statistical tools. Data analysis was conducted using statistical techniques, including percentages, frequency distributions, and logistic regression analysis. The descriptive statistical techniques were mainly used to present data regarding the frequency and percentage distribution of responses pertaining to the socio-demographic characteristics of the respondents, level of compliance to the protective behavioral recommendations, reasons for non-compliance, and beliefs about the protective behavioral recommendations. The logistic regression test was used to examine the association between the socio-demographic characteristics of respondents and their compliance to the protective behavioral recommendations. In this case, independent variables having a significance level $\leq 0.05$ were considered to be significantly associated with the dependent variable, and those having a significance level $>0.05$ were considered as not significantly associated.

\section{RESULTS}

The mean age of respondents has been found to be 24.6 $(S D=6.87)$. According to the data presented in Table $\mathbf{1}$, 
TABLE 2 | Distribution of compliance to personal protective behavioral recommendations.

\begin{tabular}{|c|c|c|}
\hline Variables & Categories & Frequency (\%) \\
\hline \multirow[t]{2}{*}{ Do you believe that a mask can prevent the transmission of COVID-19? } & Yes & $267(70.4 \%)$ \\
\hline & No & $112(29.6 \%)$ \\
\hline \multirow[t]{2}{*}{ Do you regularly wear a mask? } & Yes & $134(35.4 \%)$ \\
\hline & No & $245(64.6 \%)$ \\
\hline \multirow[t]{2}{*}{ Do you believe that cleaning hands immediately after touching any object can prevent COVID-19? } & Yes & $277(73.3 \%)$ \\
\hline & No & $102(26.9 \%)$ \\
\hline \multirow[t]{2}{*}{ Do you frequently wash your hand after touching objects? } & Yes & $216(57 \%)$ \\
\hline & No & $163(43 \%)$ \\
\hline \multirow[t]{3}{*}{ Where you can't get access to water and soap, do you clean your hand with disinfectants after touching objects? } & Yes & $171(45.1 \%)$ \\
\hline & No & $208(54.9 \%)$ \\
\hline & Total & $379(100 \%)$ \\
\hline
\end{tabular}

$57.5 \%$ of research participants are men and $42.5 \%$ are women. Furthermore, the educational background of the respondents reveals that most $(29.6 \%)$ have attended secondary level education, followed by primary level education (25.3\%), BA/BSc degree $(16.9 \%)$, and college diploma $(15.3 \%)$. It is also found that $59.1 \%$ of respondents have never been married and $35.9 \%$ are married. In addition, $66.5 \%$ of the survey participants did not have children during the time of data collection. Moreover, the majority $(68.1 \%)$ of respondents disclosed that they regularly attend any media regarding the preventive mechanisms of COVID-19. It is also found that $72.3 \%$ of research participants believe that COVID-19 really exists in Ethiopia, whereas $56.5 \%$ of them believe that COVID-19 exists in the study area. Above all, most (79.9\%) of the respondents disclosed that there is no one they know who was ever infected by COVID-19 and $84.2 \%$ replied that they do not know anyone who died of COVID-19. Data have also shown that $55.4 \%$ of respondents do not think they will be infected by COVID-19, whereas $56.5 \%$ of them perceive that they are not likely to die if infected by COVID-19. Importantly, $69.1 \%$ of respondents think that COVID-19 causes a severe illness.

\section{Compliance With Preventive Behavioral Recommendations}

Table 2 presents the frequency and percentage distributions of responses regarding the compliance of the respondents to the personal protective behavioral recommendations to contain the spread of COVID-19. Accordingly, though $70.4 \%$ of the research participants believe that a mask is effective in terms of preventing the transmission of COVID-19, only $35.4 \%$ of respondents reported to regularly wearing the mask. Furthermore, $73.3 \%$ of respondents believe that cleaning hands immediately after touching any object can prevent COVID-19 and 57\% of them disclosed that they frequently wash their hands after touching objects. Moreover, $54.9 \%$ of respondents reported that they do not clean their hands with disinfectants after touching objects under circumstances where they cannot get access to water and soap.
According to the data presented in Table 3, the most commonly reported reason of respondents for non-compliance to regular mask wearing has been its inconvenience or discomfort $(62.8 \%)$, followed by the need to appear indifferent because most people around them do not wear a mask (25.2\%), the belief that COVID-19 does not really exist (22.5\%), the belief that COVID-19 is not that serious concern in the work or residential area of the respondents (19.8\%), and perceptions of lower risk of infection by COVID-19 (19.8\%). In addition, lack of access to water and soap (58.3\%), the belief that COVID19 does not really exist (35.4\%), the belief that COVID-19 is not that serious concern in the work or residential area of the respondents $(25.1 \%)$, and reasons related to religion (14.3\%) have constituted the main reasons that respondents do not frequently wash their hands after touching objects. Above all, lack of access to hand sanitizer/alcohol (58.5\%), the belief that COVID-19 does not really exist (28.5\%), the belief that COVID-19 is not that serious concern in the work or residential area of the respondents (25.1\%), perceptions of lower risk of infection by COVID$19(20.8 \%)$, the absence of belief that cleaning hands with disinfectants prevents infection (19.8\%), and lack of adequate information (12.1\%) have been found to be the main reasons for not cleaning hands with disinfectants after touching objects among the respondents.

Table 4 presents data pertaining to the extent (frequency) to which respondents comply with the major protective behavioral recommendations to contain the spread of COVID-19. It is found that $64.9 \%$ of respondents reported to occasionally wearing a mask and $9.2 \%$ said they never wore a mask. Moreover, $51.7 \%$ of respondents occasionally engage in frequent hand hygiene practices whereas $37.7 \%$ reported to regularly keep hand hygiene. Furthermore, $42.5 \%$ of the survey participants replied that they never keep adequate physical distance during public gatherings. Around $54.4 \%$ of the respondents disclosed habits of covering mouth and nose with flexed elbow or tissue when coughing or sneezing. In addition, $57.8 \%$ of the research participants never stay at home when they are feeling sick or symptomatic of COVID-19. It is also shown that $36.1 \%$ always participate in mass events (attending religious/cultural rituals, business/work meetings, social gatherings, etc.) while $58.6 \%$ of 
TABLE 3 | Reasons of the respondents for non-compliance to personal protective behavioral recommendations.

Reasons for not regularly wearing a mask

Due to its inconvenience/discomfort

I just want to appear indifferent because most people around me do not wear mask

I can't afford to buy one because of its cost

$19(3.6 \%)$

$7.4 \%$

I don't believe that a mask can prevent infection

$39(7.4 \%)$

$15.1 \%$

I don't believe that COVID-19 really exists

$58(11.0 \%)$

$22.5 \%$

I believe that I have adequate natural immunity

$6(1.1 \%)$

$2.3 \%$

I believe that I am not at risk of being infected by COVID-19

$51(9.7 \%)$

$19.8 \%$

I believe that I can easily withstand the illness if infected by the disease

$6(1.1 \%)$

$2.3 \%$

Lack of adequate information about it

$14(2.7 \%)$

$5.4 \%$

Reasons related to belief/religion

$33(6.3 \%)$

$12.8 \%$

COVID-19 is not that serious concern in my work or residential area

$51(9.7 \%)$

$19.8 \%$

Other reasons

$17(3.2 \%)$

$6.6 \%$

No reason

$4(0.8 \%)$

$1.6 \%$

Total

Reasons for not frequently washing hands after touching objects

I avoid touching of objects from the outset

I don't believe that COVID-19 really exists

$7(2.0 \%)$

I don't believe that washing hands can prevent infection

$62(17.8 \%)$

$35.4 \%$

Because I use chemical disinfectants instead of washing my hands

$23(6.6 \%)$

$13.1 \%$

I believe that I have adequate natural immunity

$20(5.7 \%)$

$11.4 \%$

I believe that I am not at risk of being infected by COVID-19

$6(1.7 \%)$

$34(9.8 \%)$

$3.4 \%$

I believe that I can easily withstand the illness if infected by the disease

COVID-19 is not that serious concern in my work or residential area

Reasons for not cleaning hands with disinfectants after touching objects

Lack of access to hand sanitizer/alcohol

I avoid touching of objects from the outset

them do it occasionally. Above all, 34.3\% reported to always shake hands, $32.2 \%$ of respondents disclosed that they would always touch their face, and $62.2 \%$ of them do the same occasionally. Occasional eating of raw/fresh foods (raw meat, vegetables, etc.) before cooking or washing has also been reported among $57 \%$ of the research participants.

\section{Factors Affecting Compliance to} Preventive Behavioral Recommendations

The data presented in Table 5 show that the experiences of the respondents of regular mask wearing are significantly associated with regular attendance of the media regarding the preventive mechanisms of COVID-19 (OR $=0.224 ; P<0.001$; 95\% C.I: 
TABLE 4 | Extent of practices and compliances with the major protective behavioral recommendations.

\begin{tabular}{|c|c|c|}
\hline Variables/questions & Categories of responses & Frequency (\%) \\
\hline \multirow[t]{3}{*}{ Wearing a (medical) mask } & Always & 98 (25.9\%) \\
\hline & Occasionally & $246(64.9 \%)$ \\
\hline & Never & $35(9.2 \%)$ \\
\hline \multirow[t]{3}{*}{ Frequent hand hygiene (use hand sanitizers, recurrent washing of hands with soaps, etc.) } & Always & $143(37.7 \%)$ \\
\hline & Occasionally & $196(51.7 \%)$ \\
\hline & Never & $40(10.6 \%)$ \\
\hline \multirow[t]{3}{*}{ Keeping adequate (up to 2 meters) physical distance during gatherings } & Always & $34(9 \%)$ \\
\hline & Occasionally & $184(48.5 \%)$ \\
\hline & Never & $161(42.5 \%)$ \\
\hline \multirow[t]{3}{*}{ Keeping your mask clean (by washing or replacing it with a new one) } & Always & $176(46.4 \%)$ \\
\hline & Occasionally & $162(42.7 \%)$ \\
\hline & Never & $41(10.8 \%)$ \\
\hline \multirow[t]{3}{*}{ Covering mouth and nose with flexed elbow or tissue when coughing or sneezing } & Always & $136(35.9 \%)$ \\
\hline & Occasionally & $206(54.4 \%)$ \\
\hline & Never & $37(9.8 \%)$ \\
\hline \multirow[t]{3}{*}{ Staying at home when feel sick/symptomatic } & Always & $42(11.1 \%)$ \\
\hline & Occasionally & $118(31.1 \%)$ \\
\hline & Never & $219(57.8 \%)$ \\
\hline \multirow[t]{3}{*}{ Shaking hands with any person } & Always & $130(34.3 \%)$ \\
\hline & Occasionally & $184(48.5 \%)$ \\
\hline & Never & $65(17.2 \%)$ \\
\hline \multirow[t]{3}{*}{ Touching one's face (i.e., eyes, nose, and mouth) } & Always & $122(32.2 \%)$ \\
\hline & Occasionally & $232(61.2 \%)$ \\
\hline & Never & $25(6.6 \%)$ \\
\hline \multirow[t]{3}{*}{ Eating raw/fresh foods (raw meat, vegetables, etc.) before cooking or washing } & Always & $23(6.1 \%)$ \\
\hline & Occasionally & $216(57 \%)$ \\
\hline & Never & $140(36.9 \%)$ \\
\hline \multirow[t]{3}{*}{ Participating in mass events (attending religious/cultural rituals, business/work meetings, social gatherings, etc.) } & Always & $137(36.1 \%)$ \\
\hline & Occasionally & $222(58.6 \%)$ \\
\hline & Never & $20(5.3 \%)$ \\
\hline Total & & $379(100 \%)$ \\
\hline
\end{tabular}

0.109-0.460), knowledge of someone ever infected by COVID$19(\mathrm{OR}=0.402 ; P<0.05 ; 95 \%$ C.I: $0.190-0.851)$, the belief that COVID-19 causes severe illness (OR $=0.444 ; P<0.05 ; 95 \%$ C.I: $0.201-0.980$ ), and perception of the probability of dying as a result of infection by COVID-19 (OR $=0.374 ; P<0.01 ; 95 \%$ C.I: 0.197-0.711).

Results of binary logistic regression coefficients presented in Table 6 reveal that the experiences of the research participants of regularly washing hands after touching objects are significantly associated with regular attendance of the media regarding the preventive mechanisms of COVID-19 (OR $=0.467 ; P<0.05$; 95\% C.I: $0.256-0.852)$, having children $(\mathrm{OR}=0.347 ; P<0.05$; 95\% C.I: $0.137-0.878$ ), the belief that frequently washing hands helps to prevent the transmission of COVID-19 (OR = 9.871; $P<0.001 ; 95 \%$ C.I: 4.245-22.954), and age (OR $=1.050$; $P<0.05$; 95\% C.I: $1.003-1.100)$.

The data presented in Table 7 show coefficients of multinomial logistic regression pertaining to the association between the socio-demographic characteristics of the respondents and the frequency by which they practice protective behavioral recommendations. Accordingly, it is found that respondents with a better educational status $(\mathrm{OR}=0.035$; $P<0.05$; 95\% C.I: $0.002-0.595)$, those who think that they can be infected by COVID-19 (OR $=58.942 ; P<0.001 ; 95 \%$ C.I: 7.703-451.023), and those who believe that wearing mask prevents the transmission of COVID-19 (OR = 7.732; $P<0.005$; 95\% C.I: $1.332-44.893$ ) tend to regularly wear a mask.

Moreover, respondents with a better educational status (OR $=0.133 ; P<0.05 ; 95 \%$ C.I: $0.021-0.839$ ), who believe that wearing a mask prevents the transmission of COVID-19 $(\mathrm{OR}=5.550 ; P<0.001 ; 95 \%$ C.I: $1.549-19.882)$, and those who think that they are likely to be infected by COVID-19 $(\mathrm{OR}=4.113 ; P<0.05 ; 95 \%$ C.I: $1.253-13.503)$ are found to regularly engage in frequent hand hygiene (use hand sanitizers, recurrent washing of hands with soaps, etc.) practices. Above all, experiences of regularly shaking hands with someone have been found to be significantly associated with thinking that one is likely to be infected by COVID-19 (OR $=0.278 ; P<0.05$; 
TABLE 5 | Binary logistic regression showing association between socio-demographic characteristics and practices of regular mask wear.

\begin{tabular}{|c|c|c|c|c|c|c|c|}
\hline Variables & Categories & \multicolumn{3}{|c|}{ Do you regularly wear a mask? } & \multicolumn{3}{|c|}{ Logistic Regression statistics } \\
\hline Regular attendance of media & No & 13 & 108 & 121 & & & \\
\hline \multirow[t]{2}{*}{ Sex } & Male & 87 & 131 & 131 & 0.118 & 0.647 & $0.375-1.116$ \\
\hline & Female & 47 & 114 & 161 & & & \\
\hline \multirow{3}{*}{ Marital status } & Married & 47 & 89 & 136 & & & \\
\hline & Divorced & 2 & 10 & 12 & & & \\
\hline & Widowed & 1 & 6 & 7 & & & \\
\hline \multirow[t]{2}{*}{ Have children } & Yes & 46 & 81 & 127 & 0.257 & 0.571 & $0.217-1.504$ \\
\hline & No & 88 & 164 & 252 & & & \\
\hline Education & BA/BSc degree & 29 & 35 & 64 & & & \\
\hline \multirow[t]{2}{*}{ Believe that COVID-19 exists in Ethiopia } & Yes & 118 & 156 & 274 & 0.890 & 0.939 & $0.385-2.288$ \\
\hline & No & 16 & 89 & 105 & & & \\
\hline \multirow[t]{2}{*}{ Believe that COVID-19 exists in the study area } & Yes & 97 & 117 & 214 & 0.684 & 1.167 & $0.554-2.457$ \\
\hline & No & 37 & 128 & 165 & & & \\
\hline \multirow[t]{2}{*}{ Knowledge of someone ever infected by COVID-19 } & Yes & 44 & 32 & 76 & $0.017^{\star}$ & 0.402 & $0.190-0.851$ \\
\hline & No & 90 & 213 & 303 & & & \\
\hline \multirow[t]{2}{*}{ Know someone died of COVID-19 } & Yes & 30 & 30 & 60 & 0.446 & 1.373 & $0.607-3.103$ \\
\hline & No & 104 & 215 & 319 & & & \\
\hline Think can be infected by COVID-19 & Yes & 95 & 74 & 169 & 0.082 & 0.565 & $0.297-1.074$ \\
\hline Age & & & & & 0.127 & 0.959 & $0.909-1.012$ \\
\hline
\end{tabular}

${ }^{\star * *} P<0.001,{ }^{\star *} P<0.01,{ }^{*} P<0.05$

$O R$, odds ratio; C.I, confidence interval.

95\% C.I: $0.102-0.759)$ and the belief that a mask can prevent the transmission of COVID-19 (OR $=0.146 ; P<0.01 ; 95 \%$ C.I: $0.036-0.590)$.

\section{DISCUSSION}

During the period where COVID-19 pandemic has entered into a new stage of very fast spread across the world, the healthcare systems of most countries face shortages of personnel and medical equipment supplies to treat the critically ill (2). Therefore, all members of the society must understand and practice measures for self-protection and for prevention of transmission of infection to others $(5,6)$. Especially, in developing countries, such as Ethiopia, where access to
COVID-19 vaccine to every citizen is difficult to achieve, the most important way to control the disease among the populations is the regular wearing of mask, regular hand washing, the use of disinfectants, and the prevention of contact with the face and mouth after interacting with the infected environment (7). Regardless of the advocacies made by the media and numerous organizations about the need for preventing the spread of the pandemic, including the various ways of transmission, there still exists a gap as far as compliance to regular implementation of the preventive mechanisms within communities is concerned (8). The purpose of the present study was to examine the experiences of compliance to personal protective behavioral recommendations (non-pharmaceutical interventions) to contain the spread of COVID-19 among urban residents 
TABLE 6 | Binary logistic regression showing association between the socio-demographic characteristics of the respondents and practices of frequent hand wash.

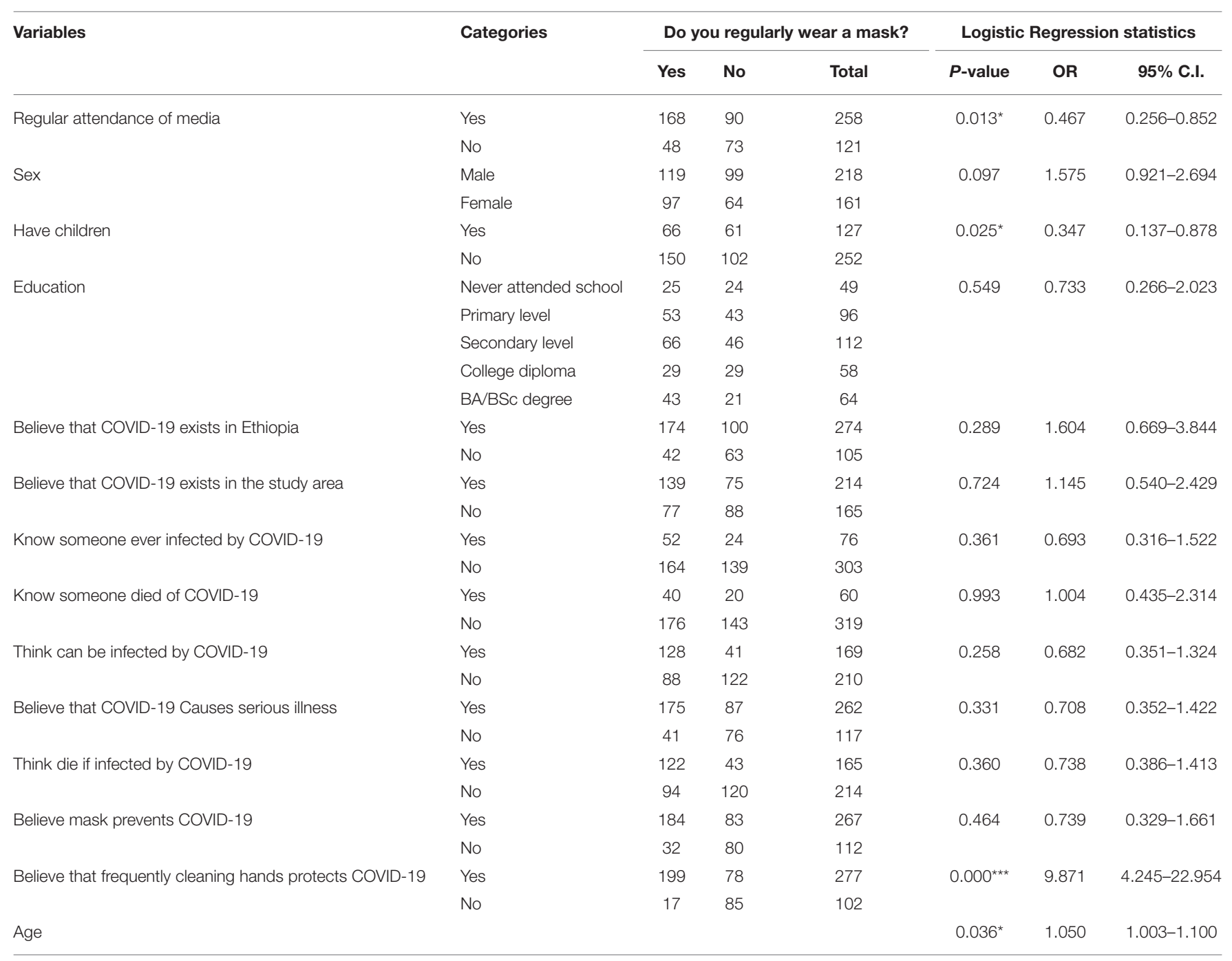

${ }^{\star \star \star *} P<0.001,{ }^{* \star} P<0.01,{ }^{*} P<0.05$.

OR, Odds Ratio; C.I, Confidence Interval.

working in the informal economic activities in Wolaita Sodo town, southern Ethiopia.

The results of the research indicated that only $35.4 \%$ of the respondents regularly wore a mask. In addition, 54.9\% of survey participants disclosed that they do not clean their hands with disinfectants after touching objects under circumstances where they cannot get access to water and soap. Furthermore, $64.9 \%$ of respondents reported to occasionally wearing a mask and $9.2 \%$ said they never wore a mask. Moreover, $51.7 \%$ of respondents occasionally engage in frequent hand hygiene practices, whereas $37.7 \%$ reported to regularly keep hand hygiene. Furthermore, $42.5 \%$ of survey participants replied to never keep adequate physical distance during public gatherings. The finding of the present study that there is a low practice of wearing mask contradicts the findings of previous studies undertaken in other parts of the world. For instance, Zhong et al. (20) found that nearly all of the participants (98.0\%) wore masks. In addition, Azlan et al. (21) revealed that most participants were taking precautions such as avoiding crowds $(83.4 \%)$ and practicing proper hand hygiene $(87.8 \%)$ in the week before the movement-control order started. He also found $51.2 \%$ practices of wearing face masks, which the authors regarded as a "less common" practice. Furthermore, Czeisler et al. (22) found widespread adherence to recommended COVID-19 mitigation strategies in the United States of America, in which 79.5\% reported the behavior of always or often keeping $\geq 6$ feet apart from others. Tomczyk et al. (16) found high compliance (25\%) with all recommendations; public compliance (51\%), with high compliance regarding public but not personal behaviors; and low compliance (24\%) with most behavioral recommendations that help to contain infection of COVID-19, where low compliance is associated with male gender, younger age, and lower public stigma. 
TABLE 7 | Multinomial logistic regression coefficients.

\begin{tabular}{|c|c|c|c|c|}
\hline Wearing a (medical) mask & & $P$-value & OR & $95 \% \mathrm{Cl}$ \\
\hline \multirow[t]{3}{*}{ Regularly } & Education & $0.020^{*}$ & 0.035 & $0.002-0.595$ \\
\hline & Think can be infected by COVID-19 & $0.000^{\star \star \star}$ & 58.942 & $7.703-451.023$ \\
\hline & Believe mask prevents COVID-19 & $0.023^{\star}$ & 7.732 & $1.332-44.893$ \\
\hline \multirow[t]{5}{*}{ Occasionally } & Education & $0.047^{\star}$ & 0.066 & $0.004-0.966$ \\
\hline & Think can be infected by COVID-19 & $0.000^{\star \star *}$ & 41.572 & $5.817-297.105$ \\
\hline & Believe that COVID-19 Causes serious illness & $0.019^{*}$ & 0.188 & $0.046-0.758$ \\
\hline & Think die if infected by COVID-19 & $0.080^{\star}$ & 0.279 & $0.067-1.167$ \\
\hline & Believe mask prevents COVID-19 & $0.001^{\star \star}$ & 15.989 & $3.318-77.061$ \\
\hline \multirow[t]{4}{*}{ Regularly } & Frequent hand hygiene (use hand sanitizers, recurrent washing of hands with soaps, etc.) & & & \\
\hline & Education & $0.032^{*}$ & 0.133 & $0.021-0.839$ \\
\hline & Think can be infected by COVID-19 & $0.020^{\star}$ & 4.113 & $1.253-13.503$ \\
\hline & Believe mask prevents COVID-19 & $0.008^{\star \star}$ & 5.550 & $1.549-19.882$ \\
\hline \multirow[t]{3}{*}{ Occasionally } & Marital status & $0.000^{\star * *}$ & 1.965 & $4.688-8.235$ \\
\hline & Education & $0.007^{* \star}$ & 0.080 & $0.013-0.498$ \\
\hline & Believe mask prevents COVID-19 & $0.013^{\star}$ & 4.216 & $1.359-13.080$ \\
\hline \multicolumn{5}{|l|}{ Shaking hands with any person } \\
\hline \multirow[t]{2}{*}{ Regularly } & Think can be infected by COVID-19 & $0.012^{*}$ & 0.278 & $0.102-0.759$ \\
\hline & Believe mask prevents COVID-19 & $0.007^{\star \star}$ & 0.146 & $0.036-0.590$ \\
\hline
\end{tabular}

The reference category is: never; ${ }^{\star \star \star} P<0.001,{ }^{\star \star} P<0.01,{ }^{\star} P<0.05$.

OR, Odds Ratio; C.I, Confidence Interval.

The findings of the study reveal a clear gap between the widely held belief about self-protection against COVID-19 and practices of implementing the recommended safety measures. For instance, $70.4 \%$ of respondents believe that a mask is effective in terms of preventing the transmission of COVID19 , and $73.3 \%$ of respondents believe that cleaning hands immediately after touching any object can prevent COVID19. The findings of the present study that most research participants have a positive attitude toward the recommended protective measures are consistent with the findings of previous studies. A study undertaken in Addis Ababa, Ethiopia by Desalegn et al. (14) found a positive attitude held among most $(60.7 \%)$ of the respondents. Another study Yonas Akalu et al. (13) stated that more than half $(54.11 \%)$ of the research participants have inadequate knowledge about the prevention of COVID-19 in Ethiopia. Moreover, Alrubaiee et al. (23) concluded that the majority of health care providers in Yemen had adequate knowledge, optimistic attitude, moderate level of anxiety, and high-performance in preventive behaviors, 69.8, $85.10,51.0$, and $87.70 \%$, respectively, toward COVID-19. AlHanawi et al. (24) also found that Saudi residents, especially women, have good knowledge, positive attitudes, and good practices toward COVID-19.

The results of our study have also revealed that the experiences of regular mask wearing of the respondents are significantly associated with regular attendance of the media regarding the preventive mechanisms of COVID-19, knowledge of someone ever infected by COVID-19, the belief that COVID-19 causes severe illness, and perception of the probability of dying as a result of infection by COVID-19. Moreover, it is also found that the experiences of research participants of regularly washing hands after touching objects is significantly associated with regular attendance of the media regarding the preventive mechanisms of COVID-19, having children, the belief that frequently washing hands helps to prevent the transmission of COVID-19, and age. Bashirian et al. (25) stated that threat and coping appraisal were predictors of protection motivation to conduct COVID-19 preventive behaviors. A study conducted by Shahnazi et al. (26) indicated that female sex, perceived barriers, perceived self-efficacy, fatalistic beliefs, perceived interests, and living in the city had the greatest preventive behaviors from COVID-19, respectively. Moreover, the presence of a strong relationship between perceived credibility of information sources about COVID-19 and engagement of peoples in self-protective behaviors has been found by Lep et al. (15). Tomczyk et al. (16) argued that low compliance to protective behavioral recommendations is associated with male gender, younger age, and lower public stigma. According to the health belief model, the key variables that determine the health behavior of an individual include perceived severity of an illness, whether the person thinks he is susceptible to certain ill-health conditions, perceived benefits that the person is likely to obtain as a result of engaging in a prohealth behavior, perceived barriers, the extent to which the individual is exposed to external events that prompt a desire to make a health change, and the self-efficacy of a person of bringing a health-related change (27-29).

\section{CONCLUSIONS}

The main objective of the present research was to assess the level of compliance to the personal protective behavioral 
recommendations (non-pharmaceutical interventions) among the urban dwellers in Wolaita Sodo town working in the informal economic activities. The results of the study indicated that people engaged in the urban informal economy have a positive attitude toward the necessity of practicing protective behaviors that help to contain the spread of COVID-19. Nevertheless, we have found a low level of compliance to the recommended safety measures, especially wearing masks. The commonly identified reasons for the low compliance have been feelings of discomfort when wearing a mask, believing that COVID-19 does not exist at all or that it is not a serious concern in the residential or workplaces of the respondents, and perceptions of being at a lower risk of infection. Moreover, the study has also revealed that regular mask wearing among the research participants is significantly influenced by the experiences of regularly attending the media, knowledge of someone infected by COVID-19, the belief that COVID-19 causes a severe illness, and perception of the probability of dying as a result of infection by COVID19. The findings of the study have great implications, especially when it comes to vulnerability and public health concerns. As in the case of the participants of the present study, urban dwellers whose livelihood predominantly relies on the informal economy characterized by irregular and unpredictable income should always remain outside of their homes in order to secure daily bread. These societal groups do not have the means to stay at home, even on witnessing the symptoms of COVID-19. This and many other characteristics of the group put them relatively at a higher risk of infection. It is therefore important that continued efforts of raising awareness should be done by all the concerned bodies. In addition, the government and other agencies in the area should devise mechanisms by which members of such group can get free access to the basic protective devices. Above all, urban safety net programs that aim at keeping such social groups at home at least during the critical wave of the pandemic should also be strengthened.

\section{REFERENCES}

1. Parasher A. COVID-19: Current understanding of its pathophysiology, clinical presentation and treatment. Postgrad Med J. (2020) 0:1-9. doi: 10.1136/postgradmedj-2020-138577

2. ERC. Covid-19 Guidelines. European Resuscitation Council (2020). Available online at: https://cms.erc.edu/sites/5714e77d5e615861f00f7d18/content_ entry5ea884fa4c84867335e4d1ff/5ed660394c84866fd4e4d19c/files/ERC_ covid19_section3.pdf?1596788172

3. Gilmore B, Ndejjo $\mathrm{R}$, Tchetchia A, de Claro V, Mago E, Diallo AA, et al. Community engagement for COVID-19 prevention and control: a rapid evidence synthesis. BMJ Global Health. (2020) 5:e003188. doi: 10.1136/bmjgh-2020-0 03188

4. Qian X, Ren R, Wang Y, Guo Y, Fang J, Wu Z, et al. Fighting against the common enemy of COVID-19: a practice of building a community with a shared future for mankind. Infect Dis Poverty. (2020) 9:34 doi: 10.1186/s40249-020-00650-1

5. Bedford J, Enria D, Giesecke J, Heymann DL, Ihekweazu C, Kobinger G, et al. COVID-19: towards controlling of a pandemic. Lancet. (2020). 395:1015-8. doi: 10.1016/S0140-6736(20)30673-5

\section{DATA AVAILABILITY STATEMENT}

The raw data supporting the conclusions of this article will be made available by the authors, without undue reservation.

\section{ETHICS STATEMENT}

The studies involving human participants were reviewed and approved by Wolaita Sodo University Ethics approval committee. Written informed consent for participation was not required for this study in accordance with the national legislation and the institutional requirements.

\section{AUTHOR CONTRIBUTIONS}

$\mathrm{BZ}$ reviewed literatures and wrote the research proposal. TH, MT, WS, and BM carried out fieldwork and drafted the manuscript. All contributed to the conception, analysis and writing of the manuscript. All authors read and approved the final manuscript.

\section{ACKNOWLEDGMENTS}

The authors would like to extend their gratitude to the duplication unit staff of Wolaita Sodo University for their unreserved help in the process of duplicating the questionnaires. Finally, all respondents who have willfully devoted their time in filling the questionnaires also deserve appreciation.

\section{SUPPLEMENTARY MATERIAL}

The Supplementary Material for this article can be found online at: https://www.frontiersin.org/articles/10.3389/fpubh. 2021.716814/full\#supplementary-material

6. WHO. Rational Use of Personal Protective Equipment for Coronavirus Disease (COVID-19) And Considerations During Severe Shortages: Interim Guidance. (2020)

7. Esakandari H, Nabi-Afjadi M, Fakkari-Afjadi J, Farahmandian N, Miresmaeil MS, Bahreini E. A comprehensive review of COVID-19 Characteristics. Biological Procedures Online. (2020) 22:1-10. doi: 10.1186/s12575-02000128-2

8. Kassa AM, Mekonnen AM, Yesuf KA, Tadesse AW, Bogale GG. Knowledge level and factors influencing prevention of COVID-19 pandemic among residents of Dessie and Kombolcha City administrations, North-East Ethiopia: a population-based cross-sectional study. BMJ Open. (2020) 10:e044202. doi: 10.1136/bmjopen-2020-044202

9. Prüb_BM. Current state of the first COVID-19 vaccines. Vaccines. (2021) 9:30. doi: 10.3390/vaccines9010030

10. Bekele F, Sheleme T, Fekadu G, Bekele K. Patterns and associated factors of COVID-19 knowledge, attitude, and practice among general population and health care workers: A systematic review. SAGE Open Med. (2020) 11:8. doi: 10.1177/2050312120970721

11. Wake AD. Knowledge, attitude, practice, and associated factors regarding the novel coronavirus disease (2019) (COVID-19) pandemic. Infect Drug Resist. (2020) 13:3817-32. doi: 10.2147/IDR.S275689 
12. Degu A, Nibret G, Gebrehana H, Getie A, Getne B. Knowledge and attitude toward the current pandemic corona virus disease and associated factors among pregnant women attending antenatal care in debre tabor general hospital northwest Ethiopia: An institutional-based cross-sectional study. Int J Womens Health. (2020) 13:61-71. doi: 10.2147/IJWH.S2 85552

13. Akalu Y, Ayelign B. Molla DM. Knowledge, Attitude and Practice Toward COVID-19 Among Chronic Disease Patients at Addis Zemen Hospital, Northwest Ethiopia. Infect Drug Resist. (2020) 13:1949-60. doi: 10.2147/IDR.S258736

14. Desalegn Z, Deyessa N, Teka B, Shiferaw W, Hailemariam D, Addissie A, et al. COVID-19 and the public response: Knowledge, attitude and practice of the public in mitigating the pandemic in Addis Ababa, Ethiopia. PLoS ONE. (2021) 16:e0244780. doi: 10.1371/journal.pone.0244780

15. Lep Ž, Babnik K, Hacin Beyazoglu K. Emotional Responses and SelfProtective Behavior within Days of the COVID-19 Outbreak: The Promoting Role of Information Credibility. Front Psychol. (2020) 11:1846. doi: 10.3389/fpsyg.2020.01846

16. Tomczyk S, Rahn M. and Schmidt S. Social Distancing and Stigma: Association Between Compliance with Behavioral Recommendations, Risk Perception, and Stigmatizing Attitudes during the COVID-19 Outbreak. Front Psychol. (2020) 11:1821. doi: 10.3389/fpsyg.2020.01821

17. ILO. Covid-19 and the World of Work: Impact and Policy Responses. 1st ed. International Labor Organization Monitor. Geneva (2020).

18. RCCE. Covid-19: How to include marginalized and vulnerable people in risk communication and community engagement. The Regional Risk Communication and Community Engagement (RCCE). (2020)

19. Zewude B, Habtegiorgis T. Willingness to take COVID-19 vaccine among people most at risk of exposure in Southern Ethiopia. Pragmat Obs Res. (2021):12 37-47 doi: 10.2147/POR.S313991

20. Zhong BL, Luo W, Li HM, Zhang QQ, Liu XG, Li1 WT, et al. Knowledge, attitudes, and practices toward COVID-19 among Chinese residents during the rapid rise period of the COVID-19 outbreak: a quick online cross-sectional survey. Int. J. Biol. Sci. (2020)16:1745-52 doi: 10.7150/ijbs.45221

21. Azlan AA, Hamzah MR, Sern TJ, Ayub SH, Mohamad E. Public knowledge, attitudes and practices toward COVID-19: A cross-sectional study in Malaysia. PLoS ONE. (2020) 15:e0233668. doi: 10.1371/journal.pone.0233668

22. Czeisler MÉ, Tynan MA, Howard ME, et al. Public attitudes, behaviors, and beliefs related to COVID-19, stay-at-home orders, nonessential business closures, and public health guidance - United States, New York City, and Los Angeles, May 5-12, 2020. MMWR Morb Mortal Wkly Rep. (2020) 69:75158. doi: 10.15585/mmwr.mm6924e1

23. Alrubaiee GG, Al-Qalah, TAH, Al-Aawar MSA. Knowledge, attitudes, anxiety, and preventive behaviors toward COVID-19 among health care providers in Yemen: an online cross-sectional survey. BMC Public Health. (2020) 20:1541. doi: 10.1186/s12889-020-09644-y

24. Al-Hanawi MK, Angawi K, Alshareef N, Qattan AMN, Helmy HZ, Abudawood Y, et al. Knowledge, Attitude and Practice Toward COVID-19 Among the Public in the Kingdom of Saudi Arabia: A Cross-Sectional Study. Front Public Health. (2020) 8:217. doi: 10.3389/fpubh.2020.00217

25. Bashirian S, Jenabi E, Khazaei S, Barati MA, Shahanjarini AS, Zareian S, et a. Factors associated with preventive behaviors of COVID-19 among hospital staff in Iran in 2020: an application of the Protection Motivation Theory. $J$ Hosp Infect. (2020) 105:430-3. doi: 10.1016/j.jhin.2020.04.035

26. Shahnazi H, Ahmadi-Livani M, Pahlavanzadeh B. et al. Assessing preventive health behaviors from COVID-19: a cross sectional study with health belief model in Golestan Province, Northern of Iran. Infect Dis Poverty. (2020) 9:157. doi: 10.1186/s40249-020-00776-2

27. Jones CL, Jensen JD, Scherr CL, Brown NR, Christy K, Weaver J. The health belief model as an explanatory framework in communication research: exploring parallel, serial, and moderated mediation. Health Commun. (2015) 30:566-76, doi: 10.1080/10410236.2013.873363

28. Hermann A, Hall A, Proietto A. Using the Health Belief Model to explore why women decide for or against the removal of their ovaries to reduce their risk of developing cancer. BMC Women's Health. (2018) 18:184. doi: 10.1186/s12905-018-0673-2

29. Frankenfield Kirsten M. "Health belief model of breast cancer screening for female college students”, (2009). Master's Theses and Doctoral Dissertations. (2009) p. 258. Available online at: http://commons.emich.edu/theses/258

Conflict of Interest: The authors declare that the research was conducted in the absence of any commercial or financial relationships that could be construed as a potential conflict of interest.

Publisher's Note: All claims expressed in this article are solely those of the authors and do not necessarily represent those of their affiliated organizations, or those of the publisher, the editors and the reviewers. Any product that may be evaluated in this article, or claim that may be made by its manufacturer, is not guaranteed or endorsed by the publisher.

Copyright (c) 2021 Zewude, Melese, Habtegiorgis, Tadele and Solomon. This is an open-access article distributed under the terms of the Creative Commons Attribution License (CC BY). The use, distribution or reproduction in other forums is permitted, provided the original author(s) and the copyright owner(s) are credited and that the original publication in this journal is cited, in accordance with accepted academic practice. No use, distribution or reproduction is permitted which does not comply with these terms. 